on her legs and eyes, a tongue with rungs to the red grass she stares down, my mother? to a knife? And the last one standing like a heave, flat to the wind, a poor board face,

shoulders slumped as if loaded with horseshoes? All, $m e$ ? Why is the room empty, and the dredges at the Ash gone to their afternoon pastries? I'm alone again

at the marble foot, a softness in my fingers moist over his cold arch, up and around the toes searching again through bone for an influence, again for the hot, unlimited blood of supply.

\title{
Gravitational Masses in the Dream Way
}

Here the weather has just broken. Rain detailing the leaves across the sidewalk,

ledger pages softening to meal with the spread of gasoline in the open street. I'm in a boat

built by Chagall; it is red

like the dress of the winter wedding guest

or the chairs facing Lear in the stone theatre fifty feet below. Chagall himself is standing

on the corner waiting for the light, the effulgent center to change. A netted sack of firm garden vegetables

hangs over his shoulder, green and yellow peppers impinging, two drops of milk, one on each eyelid

trickling down to the bones in his cheeks. I want to kiss him but the clouds are shifting and the hands behind 
the hospital doors, rouge-noir, are pulling him through . . . There's the odor of curry and creosote static

on the wind, gold and black cellophane wrappings around my eyes. We see through an open suitcase

at the bare feet of the painter who has resurfaced into the months away from his portrait of a cow, and from the side of the cow on the butcher's hook. We see more subtle inbred tricks of light

in the room of the world where I have docked. I am stepping out into thin air, into the first breath of mid-life I'll take like his hand that squeezes, then lightens, and disappears. 